\title{
AS CONTRIBUIÇÕES DOS ARQUÉTIPOS PARA O DESIGN DE EXPERIÊNCIA DO USUÁRIO EM INTERFACES GRÁFICAS
}

Felipe Machado de Souza, mestrando

Universidade Federal de Santa Catarina

mazafelipe@gmail.com

Francisco Antônio Pereira Fialho, Dr.

Universidade Federal de Santa Catarina

fapfialho@gmail.com

Resumo: O presente artigo pretende verificar como os arquétipos tem sido utilizados, hoje, em projetos de design de experiência do usuário nos meios que dão acesso - especificadamente as interfaces gráficas - ao consumo de bens e serviços no ciberespaço. O ciberespaço, tem se tornado um excelente ambiente de interatividade entre corporações e sujeitos que não existia há poucos anos, garantindo maior visibilidade no acirrado mercado competitivo. A interatividade possibilitada pela internet, por meio das interfaces gráficas, proporciona aos indivíduos experiências cada vez mais sofisticadas no ato de consumir. Logo, os ambientes virtuais podem ser considerados lugares propícios para proporcionar emoções e experiências significativas aos usuários por meio dos arquétipos. Termo cunhado pelo psiquiatra Carl Gustav Jung, os arquétipos são considerados as bases psíquicas que estimulam emoções e experiências intangíveis aos seres humanos. Por meio da perspectiva arquetípica é possível garantir significados profundos aos produtos e serviços, estejam eles em ambientes físicos ou virtuais. Quando bem aplicados nas estratégias das corporações, online ou offline, os arquétipos permitem liberar emoções e anseios profundos nos indivíduos, estimulando experiências positivas no ato de consumir e interagir com as corporações. Dentre as áreas que podem usufruir da potencialidade dos arquétipos está o design de experiência do usuário voltado às interfaces gráficas. Ou seja, os fatores humanos - no que se refere aos sentimentos e às emoções - têm papel central para o bom desempenho da experiência no ciberespaço, tornando os arquétipos potenciais ferramentas na construção de interfaces gráficas. Metodologicamente, o presente estudo foi realizado utilizando uma pesquisa exploratória e quantitativa, a partir de uma revisão sistemática ocorrida em cinco base de dados internacionais, entre elas: Scopus, Ebsco, Emerald, Springerlink e Science Direct. Os resultados encontrados evidenciam o estado da arte e a evolução da pesquisa sobre o uso dor arquétipos em interfaces gráficas. Basicamente, hoje, os arquétipos tem sido bastante utilizados para a construção das personas dos usuários que direcionam os projetos das interfaces gráficas, mas percebe-se que não 
foram, ainda, utilizados com a mesma eficácia que na construção e posicionamento de marcas.

Palavras-chave: Design de Experiência do Usuário, Emoções, Arquétipos, Interfaces Gráficas, Personas.

\begin{abstract}
This article aims to verify how the archetypes have been used today in user experience design projects in ways that give access - specifically the GUIs the consumption of goods and services in cyberspace. Cyberspace has become an excellent environment for interaction between corporations and individuals that did not exist a few years ago, ensuring greater visibility in the fierce competitive market. The interactivity made possible by the internet, through GUIs, provides individuals increasingly sophisticated experiences in the act of consuming. Therefore, virtual environments can be considered favorable places to provide significant emotions and experiences to users through the archetypes. Term coined by psychiatrist Carl Gustav Jung, the archetypes are considered psychic bases that stimulate emotions and intangible experiences to humans. Through the archetypal perspective can ensure deep meanings to products and services, whether they are in physical or virtual environments. When properly applied the strategies of corporations, online or offline, the archetypes allow release deep emotions and anxieties on individuals, stimulating positive experiences in the act of consuming and interacting with corporations. Among the areas that can take advantage of the potential of the archetypes is the user experience design geared to GUIs. In other words, human factors - with regard to the feelings and emotions - is central to the performance of experience in cyberspace, making the potential archetypes tools to build GUls. Methodologically, this study was conducted using an exploratory and quantitative research from a systematic review in five international database, including: Scopus, Ebsco, Emerald, SpringerLink and Science Direct. Our results show the state of the art and evolution of research on the use pain archetypes in GUIs. Basically, today, the archetypes have been widely used for the construction of personas of users that drive the projects of graphical interfaces, but it is clear they were not also used with the same effectiveness as in building and positioning brands.
\end{abstract}

Key-words: User Experience, Emotions, Archetypes, Graphic Interface, Personas.

\title{
1. INTRODUÇÃO
}

A sociedade contemporânea atravessa uma radical mudança no paradigma dos rituais e práticas de consumo (LEMOS, 2013). O avanço das novas mídias e a emergência da cibercultura - com seus códigos, estruturas e especificidades próprias têm transformado o modo de como grande parte dos indivíduos se comporta e se relaciona com o mundo e, entre outras coisas, com o ato de consumir bens e serviços. 
Após o advento da cibercultura, a interatividade permitida entre as corporações e os consumidores - por intermédio das novas mídias, internet e interfaces gráficas - reflete diretamente nas experiências de consumo dos indivíduos. Logo, o estudo das experiências no ciberespaço tem se tornado o tema-chave do consumo contemporâneo. Afinal, os ambientes virtuais tem sido considerado lugares propícios para prover experiências intangíveis aos usuários. Sendo assim, produzir experiências positivas no ciberespaço tem alto impacto nos resultados de consumo de um produto ou serviço, garantindo maior visibilidade às marcas no acirrado mercado competitivo contemporâneo.

Partindo da premissa de que a experiência do usuário, no mundo virtual, pode ser considerada uma oportunidade única no mercado de consumo atual, é necessário compreendê-la e aprimorá-la. Para tanto, a partir do design de experiência do usuário, pode-se garantir experiências significativas e emocionantes aos consumidores quando estes interagem com as interfaces gráficas nas mídias digitais. Assim, o design de experiência possibilita estimular sentimentos e emoções positivas, tornando a interação homemmáquina mais humanizada. Contudo, as corporações tem estimulado emoções e significados em interfaces gráficas cooperando com os projetos de design de experiência?

A hipótese levantada por esse artigo é que os arquétipos, que referem-se as emoções e as motivações humanas mais profundas proporcionando uma estrutura firme para o senso de significado, poderiam ser uma ferramenta eficaz na concepção de interfaces gráficas a fim de proporcionar uma experiência positiva ao usuário. Considera-se que a perspectiva arquetípica oferece forte controle sobre as emoções dos indivíduos, pois se refere a condições inatas que garantem experiências intangíveis. Sendo assim, o artigo tem como objetivo analisar, por meio de uma revisão sistemática, de que forma os arquétipos hoje tem contribuído para a concepção e a arquitetura das interfaces gráficas em mídias digitais. Com o resultado da revisão sistemática pretende-se verificou-se que os estudos tem utilizado os arquétipos na construção de personas de usuários de interfaces gráficas.

\section{O PARADIGMA DO CONSUMO E A EMERGÊNCIA DA CIBERCULTURA}

Em todas as sociedades, o consumo é o mediador de práticas diárias e relações sociais (BARBOSA, 2004). Por meio da compreensão do seu fenômeno entendem-se modos de vida, costumes e comportamentos, pois ele funciona como um sistema simbólico de significação, permitindo aos indivíduos expressar crenças, valores, emoções, estilos e distinção social (CAMPBELL, 2001; McCRACKEN, 2003; BORDIEU, 2006). Logo, o seu estudo pode ser considerado um modo privilegiado de decodificar o mundo que nos rodeia (ROCHA, 2000; McCRACKEN, 2003).

Contudo, a cultura ocidental contemporânea atravessa uma radical mudança no paradigma dos rituais e práticas de consumo de produtos, serviços e marcas. A emergência da cibercultura tem interferido no modo de pensar, produzir, consumir, comunicar e, consequentemente, tem alterado as experiências cotidianas de grande parte dos indivíduos. O ciberespaço "ampliou as formas de comunicação, circulação e consumo, habilitando novas alternativas de trabalho, de comércio e de acesso a bens e serviços" (BARBOSA, ANDRADE, 2014).

André Lemos (2013) diz que a cibercultura alterou o cotidiano dos indivíduos. Segundo o autor, ela problematiza e desmaterializa a sociedade de consumo, resultando em novas formas de conceber produtos e serviços. Esse novo paradigma faz com que o consumidor imponha diversificados tipos de demandas, relacionando-se de forma diferente com produtos e serviços (BRONW, 2010). 
[...] o mundo passou por uma série de mudanças baseadas na evolução das comunicações, da informática e das tecnologias de informação [...]. O consumidor típico da sociedade de massa passou a assumir novas feições, voltadas cada vez mais para o consumo via internet, e com muito mais liberdade e instrumentos para comprar sem sair de casa, efetivar o pagamento via depósito bancário virtualmente e receber o produto ou o serviço dentro de pouco tempo (WOLTMANN; PEREIRA: KRAUSPENHAAR, 2013, p. 221-233).

Jenkins (2009, p. 47) afirma que "se os antigos consumidores eram indivíduos isolados, os novos consumidores são mais conectados socialmente". O receptor passivo deu lugar ao telespectador usuário, com uma postura mais participativa e exigente. Interativo, seletivo e informado, esse sujeito tem introduzindo novos hábitos de consumo (MONTRESOL, 2010).

Para Tim Brown (2010) a sociedade está saindo do consumo passivo para uma participação ativa, na qual cada indivíduo cria suas experiências. Logo, estas surgem como elemento norteador do consumo do homem contemporâneo. Barbosa e Campbell (2006, p. 28) explicam que "o consumo, é hoje, antes de tudo, experiência". Ou seja, não se adquire mais algo apenas pela sua usabilidade, mas, principalmente, pelas experiências que proporcionará. Então, ao que tudo indica, na atualidade a "experiência de consumo é o tema-chave" (NETO, FLORIDIA, 2008, p. 113-129).

Considerando que as experiências da vida se realizam em instâncias concretas, virtuais ou realidades mescladas é preciso um recorte epistemológico. Logo, o estudo das experiências relacionadas ao consumo se dará, nesta pesquisa, a partir das experiências oriundas do acesso à cibercultura por meio de novas mídias e interfaces digitais. Tal recorte se faz relevante porque a cibercultura tem proporcionado, aos sujeitos, experiências cada vez mais sofisticadas no ato de consumir.

\subsection{Experiências no acesso à cibercultura}

Schmitt (2000) explica que as experiências surgem a partir de acontecimentos reais, imaginários ou virtuais. Para Shedroff (2001), as experiências podem ser produzidas por meios tradicionais, físicos, offline, digitais ou online.

Ao contrário das mídias tradicionais, os ambientes digitais interativos permitem que o usuário crie experiências por meio de imagens, vídeos, textos e jogos (AUSTIN; DOUST, 2007, p. 13). Assim, internet, novas mídias e interfaces gráficas estimulam interações dos agentes envolvidos na produção e no uso de produtos e serviços. Essas tecnologias tornam-se essenciais para contribuir com o desenvolvimento de experiências positivas dos usuários ao consumir no ciberespaço.

Logo, a interatividade proporcionada por internet, mídias digitais e interfaces pode ser considerada um meio com grande capacidade de prover experiências aos usuários (MORAES, D. 2001). Essa interatividade pode estimular experiências que impactem nos resultados de consumo de bens e serviços no ciberespaço. Sendo assim, as corporações precisam inovar na mediação com suas audiências. O mundo virtual tornou-se excelente lugar de contato entre corporações e sujeitos que não existia há poucos anos, permitindo novas experiências de consumo.

Segundo Schmitt (2000), as novas mídias digitais e os ambientes virtuais são importantes provedores de experiência, mas pouco foram explorados em termos experienciais. Logo, é necessário buscar ferramentas e áreas que tratam da construção de um universo articulado entre pessoas e máquinas para um aprofundamento experiencial e imersivo do consumidor no ciberespaço. 


\subsection{Design, usuário e experiências humanas}

Visto que as experiências humanas tornaram-se relevantes para a compreensão do comportamento do consumidor na sociedade conectada, seu estudo fez emergir áreas para seu entendimento e aprimoramento. Entre elas, pode-se citar o design de experiência do usuário - ou design experiencial.

\footnotetext{
O design experiencial possui uma abordagem mais ampla que o design tradicional, esforçando-se para criar experiências, ao invés de simplesmente produtos e serviço [...]. O design experiencial é entendido como sendo a prática do design que busca não somente atender as necessidades imediatas e objetivas do usuário, mas entender e preencher as motivações e grandes experiências da vida (RIBEIRO, 2006, p. 17).
}

As explicações dadas por Ribeiro corroboram com a colocação feita por Bonsiepe (2011): "em virtude do desenvolvimento tecnológico dos meios digitais, abriram-se novas possibilidades de atuação do design." Uma dessas possibilidades é o design de experiência, que assume papel relevante no que tange ao desenvolvimento de mídias digitais e interfaces gráficas, potencializando as teorias do design tradicional. Austin e Doust (2008) explicam que o design experiencial, segundo o American Institute of Graphic Arts (AIGA), apresenta fronteiras mais amplas que o design tradicional e tem como intenção criar experiências maiores do que simples produtos e serviços conectando-se a nível emocional com o usuário. Para eles, se usa o termo design experiencial para descrever as formas em que o design gráfico incita o usuário a entrar em uma experiência emocionante.

O design de experiência apresenta-se como um novo paradigma que exige a compreensão do comportamento humano e de variáveis relacionadas à experiência do usuário. Uma de suas vertentes se propõe à delimitação de conhecimentos acerca de sentimentos, emoções e significados para prover experiências motivadoras. Assim, o design experiencial pode antecipar e respeitar o funcionamento da psique do usuário tornando a sua experiência mais intensa e aumentando o seu grau de satisfação.

Schifferstein e Hekkert (2008 apud BROGIN, 2015) explicam que o fator experiencial se refere aos significados e valores anexados aos produtos e aos sentimentos e emoções suscitados nos usuários em determinado momento. Os sentimentos e as emoções são elementos necessários à vida, afetando a maneira como um indivíduo se sente, se comporta e pensa. Com base nesses aspectos, Donald Norman $(2006 ; 2008)$ tornou-se um dos pioneiros ao expor a importância do aspecto emocional e sensorial nos produtos, criando o termo da Experiência do Usuário (UX), que tem a intenção de compreender como a emoção e o prazer influenciam a percepção do sujeito e direcionam suas ações. "As emoções refletem nossas experiências pessoais, associações e lembranças" (NORMAN, 2008, p. 68).

Para uma experiência do usuário positiva, os fatores humanos - no que se refere aos sentimentos e às emoções - têm papel central para o bom desempenho da experiência de consumo. Sendo assim, a ênfase na experiência do usuário possibilita estimular e evocar emoções benéficas, transcendendo a razão no ato de consumir. Considerando os desafios das corporações na cibercultura, quanto mais as mídias digitais e os ambientes virtuais evocarem, de maneira eficaz, fatores emocionais e experienciais, maior a chance de sucesso no mercado de consumo contemporâneo.

DAMÁSIO (1994) e NORMAN (2008) explanam que o lado emocional toma decisões de forma rápida e instintiva, possuindo raízes mais profundas que a cognição. 
Desse modo, proporcionar experiências que estimulem emoções profundas pode tornar a percepção do usuário, inconscientemente, satisfatória, potencializando os projetos de design experiencial e experiência do usuário. Contudo, tanto Damásio quanto Norman não desenvolvem argumentos indicativos claros de como as emoções podem ser ativadas e estimuladas, favorecendo os tipos de experiência de consumo.

\subsection{Arquétipos em projetos de design de experiência do usuário}

Dentre as correntes que buscam entender a psique humana, a Psicologia Analítica, do psiquiatra Carl Gustav Jung (2008), apresenta os arquétipos como uma forma de compreender o funcionamento das experiências humanas que se manifestam em contextos simbólicos e emocionais. A partir da teoria dos arquétipos é possível identificar diretrizes para orientar projetos de design de experiência do usuário, tornando-os mais profundos, envolventes e inovadores. Os arquétipos têm essa potencialidade porque "uma imagem arquetípica toca muito mais fortemente a estrutura psíquica do consumidor" (MARTINS, 2007, p. 135).

Desse modo, os arquétipos tornam-se ferramentas que podem cooperar para dar mais sentimento humano à interação homem-máquina, ultrapassando os fatores racionais e socioculturais e auxiliando as estratégias tradicionais de design de experiência. Os arquétipos podem ser considerados uma ferramenta relevante porque têm forte controle sobre a motivação e a emoção dos indivíduos e referem-se a condições fundamentalmente humanas que transcendem tempo, lugar, cultura, gênero ou idade. Para Batey (2010), "Os arquétipos representam condições fundamentais na condição humana. Eles tocam nossos motivos mais profundos e proporcionam uma estrutura firme para o senso de significado".

De acordo com Jung (2000), os arquétipos são padrões inatos de comportamento humano e, justamente por serem inatos, eles "acessam o mesmo conteúdo emocional em indivíduos de diferentes culturas e diferentes lugares do mundo" (MORAES, 2010). Os arquétipos também têm um componente dinâmico e vêm acompanhados por um forte componente emocional (FERNANDES; FIALHO, 2014).

Sendo assim,

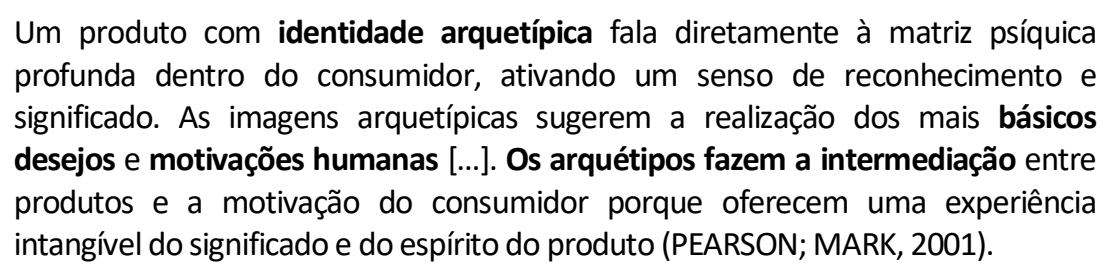

Por essas razões, acredita-se que o uso da teoria dos arquétipos na construção da experiência do usuário, por meio do design experiencial, em interfaces gráficas, permite envolver o consumidor com maior imersão, interação e participação, tanto cognitiva quanto emocional, dando maior significado às experiências no ciberespaço.

Esse artigo tem como objetivo analisar como se tem dado, nas discussões acadêmicas já publicadas, a articulação dos arquétipos com as interfaces gráficas que dão acesso ao mundo virtual. A teoria dos arquétipos pode ser uma ferramenta eficaz na construção de interfaces e, suas relações, podem complementar-se de uma maneira inovadora, levando aos webdesigners e arquitetos de sites, maneiras diferenciadas para a produção de experiências ao usuário nos meios que dão acesso ao ciberespaço. A busca por produções acadêmicas com essas temáticas se dará por meio 
de uma revisão sistemática integrativa. Essa revisão é empregada como ferramenta para medir a o estado da arte sobre determinado assunto de interesse. Fazer o levantamento do inventário das atividades científicas, nos mais diversos campos do conhecimento, implica em uma busca criteriosa nas publicações, pois o homem busca e apresenta constantemente novos conhecimentos, fazendo com que as informações circulem e se disseminem por todas as partes do mundo. A análise dos indicadores permite, por meio de análise estatística, quantificar a produção científica e técnica. Segundo Saes (2000), os indicadores são empregados por dois motivos: O primeiro é para analisar o tamanho, crescimento e distribuição da bibliografia científica (livros, revistas, patentes e outros), a fim de melhorar as atividades de informação, documentação e comunicação científica. O segundo é para analisar os processos de geração, propagação e uso da literatura científica com a finalidade de conhecermos os mecanismos da investigação cientifica enquanto atividade social e a dinâmica e estrutura dos grupos de investigadores que produzem e utilizam esta literatura.

Nesse sentido, sendo a revisão sistemática e a análise bibliométrica técnicas utilizadas para estudos métricos da informação registrada, propõe-se neste artigo uma revisão sistemática integrativa da literatura, objetivando identificar as características das publicações resultantes da junção e/ou associação das temáticas citadas, que serão representadas pelos descritores: arquétipos, design de experiência, novas mídias e interfaces gráficas.

Como propósito principal do artigo, tem-se mensurar a comunicação científica onde exista tal cruzamento por intermédio de revisão sistemática integrativa. $O$ trabalho também contempla uma análise abordando indicadores de impacto, de produtividade de autores e periódicos, filiações e publicações nos anos entre 2010 e 2016. A publicação e divulgação de trabalhos acadêmicos sobre a temática apresentada tem o potencial de gerar valiosas ferramentas de suporte a tomada de decisão para webdesigners que estejam dispostos a inovar na interatividade das interfaces gráficas, humanizando o processo homem-máquina. Bem como criar uma nova cultura na construção de websites que evidência os fatores emocionais na prática do design de experiência com a possibilidade de oferecer um diferencial consistente e inovador aos seus consumidores ao interagir com os meios que dão acesso ao ciberespaço.

\section{METODOLOGIA}

A pesquisa realizada pode ser classificada quanto ao seu objetivo como descritiva, ou seja, a pesquisa que observa, registra, analisa e correlaciona fatos ou fenômenos (variáveis) sem manipulá-los. Quanto a sua abordagem a pesquisa é quantitativa e os procedimentos técnicos adotados se enquadram no tipo denominado de documental (CERVO; BERVIAN, 2002). A abordagem quantitativa, segundo Richardson (1999), se define pelo emprego de quantificação tanto nas modalidades de coleta de informações, quanto no tratamento delas por meio de técnicas estatísticas, desde as mais simples como percentuais, médias, desvio-padrão, às mais complexas como coeficiente de correlação, análise de regressão, etc. As bases de dados pesquisadas foram exploradas online, via Biblioteca Universitária da UFSC, utilizandose também, da liberação de acesso desta à periódicos pagos. Foram escolhidas para análise as bases Scopus, Emerald, Springer e Ebsco. 


\subsection{Coleta e análise de dados}

O levantamento de dados para a compreensão do estado da arte ocorreu da seguinte forma: a) primeiramente, criou-se a pergunta da pesquisa: A teoria dos arquétipos pode contribuir para propiciar experiências e emoções positivas, aos usuários, em interfaces gráficas? b) em seguida, definiu-se, a partir do problema da pesquisa, as palavras-chave e, com elas, a estratégia de busca. As palavras-chave selecionadas foram arquétipos (achetype OR archetypal); emoções (emotion OR emotional); experiência do usuário ou design de experiência (experience design OR user experience OR user-centered design), novas mídias (digita media OR new media) e interfaces gráficas (graphical user interface). Tais palavras, nas estratégias de busca, poderiam ser encontradas no título, no resumo, nas palavras-chave ou, ainda, no texto; (b) determinou-se, como critério de inclusão, o período de publicação do material cientifico entre 2010 e 2016, compreendendo os últimos 6 anos; (c) restringiu-se a busca a somente artigos e capítulos de livros; (d) idiomas restritos a inglês, espanhol e português; (e) as bases de dados utilizadas para a pesquisa foram a Scopus, Emerald, Springer e Ebsco.

A etapa inicial da pesquisa sistemática integrativa, nas base de dados, resultou em 765 publicações, porém, após aplicado critérios de inclusão e exclusão, os resultados caíram para 426 publicações - considerando artigos de revistas, artigos de eventos e capítulos de livros. Esses resultados, ainda, passaram por novos critérios de análises mais aprofundados como, por exemplo, verificação de textos não completos disponíveis, metadados e palavras-chave. Junto a essa nova avaliação, algumas publicações ainda foram examinadas por critérios de qualidade, esses serviram para classificar e qualificar as publicações encontradas. Tais critérios foram aplicados por meio das seguintes questões: a) A proposta/objetivo foi apresentado de forma clara? b) As relações que a revisão sistemática busca estão claras? c) Os métodos utilizados e o contexto foram demonstrados? d) Os resultados foram validados? e) As referências estão atualizadas? As publicações precisavam responder, positivamente, pelo menos três desses critérios para serem incluídas nas análises da próxima e última etapa.

No montante final, restaram 240 publicações para leituras do resumo ou texto completo afim de verificar se o artigo ou capítulo poderia cooperar para compreender o estado da arte do tema almejado. Na Tabela 1, é possível verificar o resultado das análises das 240 publicações, conforme base de dados. Além disso, a Tabela 1 apresenta o número total de artigos que atenderam os critérios para compreensão das discussões científicas do assunto proposto: arquétipos, experiência do usuário, novas mídias e interfaces gráficas.

Tabela 1 - critérios utilizados e resultados por base de dados

\begin{tabular}{|c|c|c|c|c|c|c|}
\hline & $\begin{array}{l}\text { Total de } \\
\text { publicações } \\
\text { por base de } \\
\text { dados }\end{array}$ & $\begin{array}{l}\text { Texto } \\
\text { completo } \\
\text { não } \\
\text { disponível }\end{array}$ & $\begin{array}{l}\text { Análise por } \\
\text { títulos, } \\
\text { metadados e } \\
\text { palavras- } \\
\text { chave }\end{array}$ & $\begin{array}{l}\text { Artigos } \\
\text { analisados } \\
\text { por resumo }\end{array}$ & $\begin{array}{l}\text { Artigos } \\
\text { completos } \\
\text { verificados }\end{array}$ & $\begin{array}{l}\text { Total } \\
\text { relevante } \\
\text { para a } \\
\text { pesquisa }\end{array}$ \\
\hline EBSCOhost & 14 & 3 & 11 & 8 & 2 & 7 \\
\hline Scopus & 84 & 22 & 62 & 26 & 4 & 5 \\
\hline Emerald & 89 & 28 & 61 & 32 & 5 & 3 \\
\hline Springerlink & 51 & 0 & 51 & 28 & 7 & 5 \\
\hline ScienceDirect & 2 & 0 & 0 & 1 & 0 & 1 \\
\hline TOTAL & & & & & & 21 \\
\hline
\end{tabular}

Fonte: Elaborado pelo autor, com base na pesquisa realizada 
Conforme demonstrado na Tabela 1, após a última etapa, restaram 21 publicações que cooperam para mapear o atual estágio da produção intelectual sobre a possibilidade das contribuições dos arquétipos na construção de interfaces gráficas para melhor experiência do usuário em novas mídias. Logo após a leitura integral dos 21 artigos, sendo 19 em inglês e 2 em espanhol, os dados foram inseridos em formulários de extração de dados e gerenciamento, sendo esses organizados da seguinte maneira: número de identificação do artigo; base de origem; título; autor(es); periódico (journal); ano de publicação; instituição; resumo (abstract); objetivo; método; principais resultados/conclusão. Essa organização preliminar possibilitou o resumo crítico dos artigos e a posterior composição dos dados em gráficos e tabelas, os quais embasam também a sua discussão a partir de objetivos, métodos, resultados e conclusões. Abaixo, a Figura 1 apresenta a evolução dos resultados de busca nas 5 base de dados pesquisadas conforme utilização dos critérios mencionados anteriormente. Na Figura 2, apresenta-se os países dos 21 artigos selecionados para compreender o estado da arte do tema almejado.

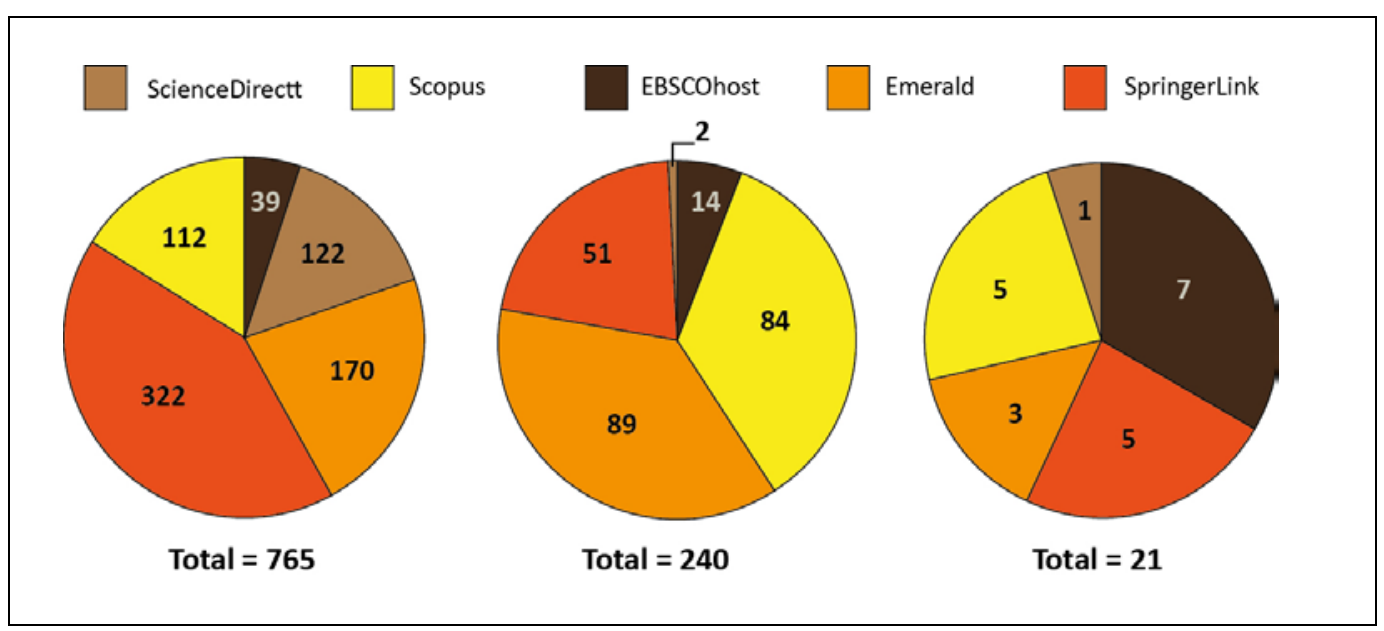

Figura 1 - Evolução da pesquisa na base de dados

Fonte: Elaborado pelo autor, com base na pesquisa realizada

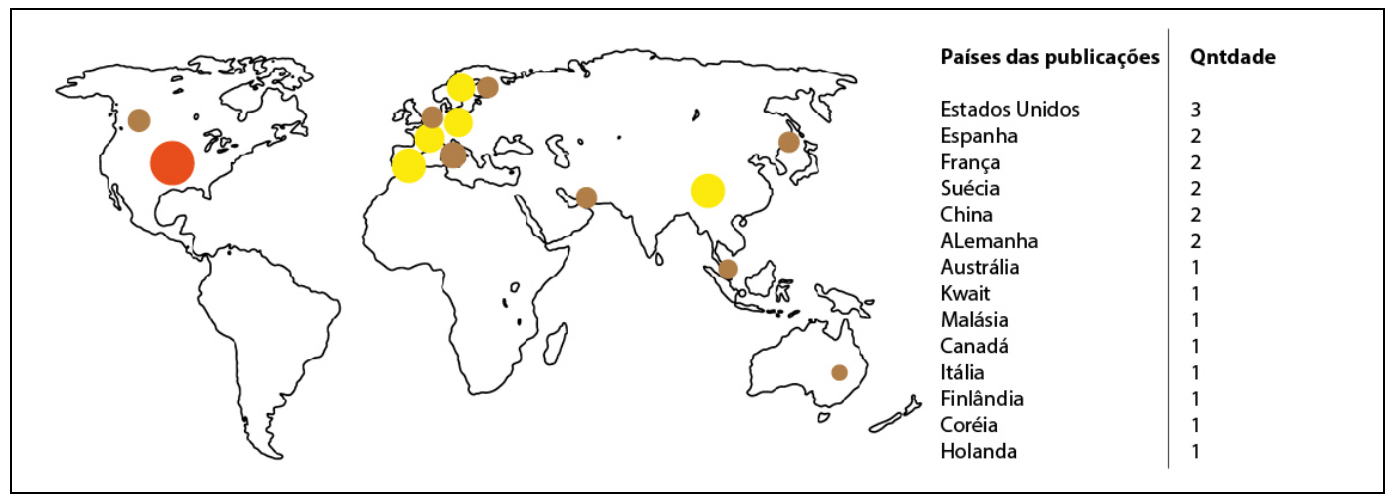

Figura 2 - Regiões em que os 21 pesquisas selecionadas foram desenvolvidos e publicados Fonte: Elaborado pelo autor, com base na pesquisa realizada

Com relação ao ano de publicação, nota-se um crescimento, com o passar dos anos, na produção de artigos sobre a importância de considerar as emoções na construção de interfaces gráficas, por meio de ferramentas arquetíticas. Embora tenha ocorrido publicações sobre a temática na década de 70, percebe-se um nítido aumento 
na quantidade de publicações nos últimos 12 anos. Esse aumento gradativo se dá, pois as novas mídias e os conceitos de interfaces gráficas são contemporâneos no contexto científico. Embora nos últimos 6 anos tenha um alto número de publicações na área, as que envolvem os temas emoções ou arquétipos ainda não é o suficiente, se considerarmos a importância do tema.

Dos 21 artigos selecionados para a discussão do tema, neste artigo, estão distribuídos da seguinte maneira: três publicações 2010, duas em 2011, quarto em 2013, três em2014, cinco em 2015 e, por fim, dois em 2016.

\section{CONCLUSÃO}

Praticamente metade dos 21 artigos escolhidos para o estado da arte abordam o tema das emoções e do seu papel na Interação Humano-Computador. Resumidamente, a maior parte deles analisam como as emoções influenciam benefícios inerentes a interface e à experiência do usuário demonstrando que, a dimensão emocional dos usuários das Tecnologias de Informação e Comunicação (TIC) é um aspecto fundamental na experiência do usuário. Logo, para projetar uma interface, a fim de proporcionar uma experiência emocional positiva, a qualidade afetiva da interface do usuário deve ser cuidadosamente considerada.

O foco principal dos artigos que discutem emoções e interfaces gráficas se limitam na relação emocional dos indivíduos com as experiências resultantes das interfaces. Um dos artigos explica que, por muito tempo, as áreas que estudavam design de interface abordavam, principalmente, as características ergonomicas e cognitivas. Mas, continua o artigo, com o crescimento dos estudos dá área, hoje, abarcou-se também os processos emocionais do usuário, buscando compreender como despertar a emoção consciente ou inconsciente por meio de uma interface gráfica (BONNARDEL; LOCKNER et al, 2014).

Embora muitos desses estudos apresentem a emoção como algo relevante a ser considerado, nenhum deles traz um procedimento de como poderia se evocar ou estimular emoções a partir do design de interfaces. Pelo contrário, conforme explica Silvennoinen e Jokinen (2016) o design de interface do usuário é bastante complexo, pois não há nenhuma fórmula universal de design visual para ser aplicado em todas as interfaces do usuário com o objetivo de provocar experiências emocionais positivas. Os elementos visuais das interfaces podem ser projetados em incontáveis e diferentes combinações, afetando os usuários de diferentes maneiras.

Para tentar afetar as emoções dos indivíduos de maneira similar, cinco dos artigos trazem as personas como uma possibilidade de criar interfaces a partir de um perfil padrão dos usuários. As personas são descrições e características dos usuários, baseado em uma síntese de pessoas reais, ou seja, não são personagens idealizados. Pelo contrário, busca-se, a partir das personas, representar as necessidades de grandes grupos de usuários, seus objetivos, características pessoais, emoções e motivacionais da forma mais verdadeira possível. Assim, projeta-se uma interface para um conjunto reduzido de personas com o objetivo de agradar todos os usuários de maneira semelhante. As personas possibilitam guiar o processo de design de interfaces, desse modo permite que os webdesigners se coloquem no lugar de seus usuários de forma universal e não na perspectiva particular do designer ou do executivo que solicita uma página de website, por exemplo. E é na construção das personas que grande parte dos artigos faz referência aos arquétipos. 
Considerando, como já foi mencionado, os arquétipos ferramentas que possibilitam orquestrar as experiências e as emoções que se pretende estimular nos usuários, percebe-se que seu uso ainda não foi utilizado com todo seu potencial. Nos artigos encontrados, quando mencionado os arquétipos, normalmente sua relação está somente na construção da persona ou de um storytelling interativo. Outro artigo explica que, é por meio de uma pesquisa de campo, que descobre-se qual arquétipo se pode utilizar para a construção da persona, desse modo, traduz-se estudos de observação do usuário em um formato de narrativa e/ou persona para aprimorar as experiências em interfaces gráficas. O estudo enfatiza o uso das personas como personagens reais fictícios que são compostos a partir de dados comportamentais recolhidos com base em uma etnografia trazendo um contexto universal, nesse sentido totalizante entra o conceito dos arquétipos, já que conforme explicado no início, o arquétipo trascente cultura, gênero, idade e época.

Sendo assim, de acordo com o estado da arte analisado nessa pesquisa, verificou-se que os arquétipos - que são ferramentas que possibilitam orquestrar as experiências e as emoções que se pretende estimular nos usuários - tem sido utilizado para uma construção de experiência do usuário positiva, em interfaces gráficas, através das personas. Embora tenha aumentado sua penetração no campo da produção de interfaces gráficas, percebe-se que o uso dos arquétipos, no ciberespaço, ainda não foi utilizado com todo seu potencial pelas corporações. Caso comparemos o uso dos arquétipos na construção das marcas, branding ou no storytelling produzido para mídias tradicionais, pode-se dizer que seu uso no mundo virtual ainda é um campo pouco explorado. Os arquétipos como elucidam Carol Pearson e Margaret Mark (2001) utilizados em produtos e serviços ativam maior senso de significado e ativam a matriz psíquica dos consumidores e usuários, mas, mesmo sabendo desse potencial, poucas corporações tem trabalhado com essa ferramenta de forma eficaz e abrangente. Seu uso tem se limitado apenas a construção da persona dos usuários, mas poder-se-ia traduzir os arquétipos a partir de uma semiótica icônica onde, provavelmente, ativaria e estimularia emoções positivas nos usuários assim como tem ocorrido com seu uso em marcas, produtos e serviços. Pretende-se, a partir desse levantamento, analisar outras possiblidades de uso dos arquétipos nos meios que dão acesso ao ciberespaço - como as interfaces gráficas - em estudos futuros.

\section{REFERÊNCIAS}

AUSTIN, T.; DOUST, R. New Media Design. London: Laurence King Pub, 2007.

BARBOSA, G; ANDRADE, L. A. de. Do oral ao hipertexto: a (re)existência do cordel na superfluidez do ciberespaço. In: VIII SIMPÓSIO ANUAL DA ASSOCIAÇÃO BRASILEIRA DE PESQUISADORES EM CIBERCULTURA (ABClber). Anais... São Paulo, SP, 2014.

BARBOSA, L. Sociedade de consumo. Rio de Janeiro: Jorge Zahar, 2004.

BARBOSA, L.; CAMPBELL, C. Cultura, consumo e identidade. Rio de Janeiro: FGV, 2006.

BATEY, M. O significado da marca: como as marcas ganham vida na mente dos consumidores. Rio de Janeiro: Best Seller, 2010.

BONSIEPE, G. Design, sociedade e cultura. São Paulo: Blucher, 2011. 
BONNARDEL, N.; LOCKNER, D.; BOUCHARD, C.; RIEUF, V. Emotion and interface design. Ergo'IA '14 - Proceedings of the 2014 Ergonomie et Informatique Avancée Conference - Design. Ergonomie et IHM: quelle articulation pour la co-conception de l'interaction. New York, 2014, p. 33-40.

table of contents ISBN: 978-1-4503-2970-5 doi>10.1145/2671470.2671475

BOURDIEU, P. A distinção: crítica social do julgamento. Porto Alegre: Zouk, 2006.

BROWN, T. Design thinking: uma metodologia poderosa para decretar o fim das velhas ideias. Rio de Janeiro: Elsevier, 2010.

CAMPBELL, C. A ética romântica e o espírito do consumismo moderno. Rio de Janeiro: Rocco, 2001.

CERVO, A. L; BERVIAN, P. A. Metodologia científica. 5 ed. São Paulo: Prentice Hall, 2002.

COELHO, N. N. O conto de fadas: símbolos, mitos e arquétipos. São Paulo: Paulinas, 1998.

DAMÁSIO, A. R. O erro de Descartes: emoção, razão e cérebro humano. São Paulo: Companhia das Letras, 1994.

GIL, A. C. Como elaborar projetos de pesquisa. São Paulo: Atlas, 2002.

JUNG, C. G. Os arquétipos e o inconsciente coletivo. Petrópolis: Vozes, 2008.

LAKATOS, E. M.; MARCONI, M. de A. Metodologia científica. São Paulo: Atlas, 2008.

LEMOS, A. Cibercultura: tecnologia e vida social na cultura contemporânea. Porto Alegre: Sulina, 2013.

LEVY, P. Cibercultura. São Paulo: Ed. 34, 1999.

LORGUS, A. L.; ODEBRECH, C. Metodologia de pesquisa aplicada ao design. Blumenau: Edifurb, 2011.

MARK, M.; PEARSON, C. S. O Herói e o Fora-da-Lei: como construir marcas extraordinárias usando o poder dos arquétipos. São Paulo: Cultrix, 2001.

MARTINS, J. S. A natureza emocional da marca. Construção de marcas líderes. Rio de Janeiro: Campus, 2007.

MCCRACKEN, G.. Cultura \& Consumo: novas abordagens ao caráter simbólico dos bens e atividades de consumo. Rio de Janeiro: Mauad, 2003.

MONTRESOL, E. C. O receptor das mídias digitais. Revista Brasileira de Biblioteconomia e Documentação, São Paulo, v. 6, n. 2, jul./dez. 2010, p. 20-35.

MORAES, D. de. 0 concreto e o virtual: mídia, cultura e tecnologia. Rio de Janeiro: DP\&A, 2001.

MORAES, F. Arquétipo e representações arquetípicas. Jung no espírito santo: Por um retorno a C. G. Jung. Disponível em: <http://psicologiaanalitica.com/arqutipo-erepresentaes-arquetpicas/>. Acesso em: 04 jun. 2015.

NETO, E. C.; FLORIDIA, G. Circuitos online de comunicação relacionada ao consumo.

Revista Comunicação, Mídia e Consumo, v. 5, n. 12, jan./abr. 2008, p. 113-129. 
NORMAN, A. Design emocional. Rio de Janeiro: Rocco, 2008.

NORMAN, A. O design do dia-a-dia. Rio de Janeiro: Rocco, 2006.

BUCCINI, M. P. R. Design experiencial em ambientes digitais: um estudo do uso de experiências em web sites e junto a designers e usuários de internet. 2006. Dissertação (Mestrado). Programa de Pós-Graduação em Design, Universidade Federal de Pernambuco, Recife, 2006.

RICHARDSON, Roberto Jarry. Metodologia da pesquisa aplicável às ciências sociais. In: Beuren, Ilse Maria (org). Como elaborar trabalhos monográficos em contabilidade: teoria e prática. 2. ed. São Paulo: Atlas, 2004.

ROCHA, E. Totem e consumo: um estudo antropológico de anúncios publicitários. Revista ALCEU, v. 1 n. 1 jul/dez. 2000, p. 18-37.

SCHMITT, Bernd. Marketing experimental. São Paulo: Nobel, 2000.

SCHIFFERSTEIN, H. N. J.; HEKKERT, P. Product Experience. Oxford, Inglaterra: Elsevier, 2008. apud BROGIN, B. Gestão de design para moda inclusiva: diretrizes de projeto para experiência do usuário com deficiência motora. 2015. Dissertação (Mestrado). Programa de Pós-Graduação em Design e Expressão Gráfica, Universidade Federal de Santa Catarina, Florianópolis, 2015.

SECRETARIA DE COMUNICAÇÃO SOCIAL DA PRESIDÊNCIA DA REPÚBLICA - SECOM. Pesquisa brasileira de mídia 2015: hábitos de consumo de mídia pela população brasileira. Brasília: SECOM, 2015.

SHEDROFF, N. Experience Design 1. Indianapolis (IN): New Riders, 2001.

SILVENNOINEN, JOHANNA M. JOKINEN, Jussi P. Appraisals of Salient Visual Elements in Web Page Design. Advances in Human-Computer Interaction. 4/19/2016, p1-14. 14p.

WOLTMANN, A.; PEREIRA, R. P.; KRAUSPENHAAR, F. Relações de consumo, cibercultura e sustentabilidade: o despertar de um "novo" consumidor. Revista Eletrônica do Curso de Direito da UFSM, v. 8, Ed. Especial, 2013, p. 221-233. 